\title{
Safety Assessment of the Human Milk-Isolated Probiotic Lactobacillus salivarius CECT5713
}

\author{
F. Lara-Villoslada, ${ }^{1}$ S. Sierra, M. P. Díaz-Ropero, M. Olivares, and J. Xaus \\ Department of Nutrition and Health, Puleva Biotech S.A. Cno. Purchil no. 66, 18004 Granada, Spain
}

\begin{abstract}
The potential probiotic bacteria Lactobacillus salivarius CECT5713 has recently been isolated from human milk and characterized. The objective of the present study was to evaluate the oral toxicity of this potential probiotic bacteria in mice. With this aim, $50 \mathrm{Balb} /$ $\mathrm{C}$ mice were divided in 5 groups $(\mathrm{n}=10)$. Three of these groups were treated orally with different doses of $L$. salivarius CECT5713: $5 \times 10^{8}, 2 \times 10^{9}$, or $10^{10} \mathrm{cfu} /$ mouse per $\mathrm{d}$ for $28 \mathrm{~d}$. One additional group was administered the vehicle alone and was used as a control. The last group were injected intraperitoneally with $10^{8} \mathrm{cfu} /$ mouse in a single dose and killed $2(\mathrm{n}=5)$ and $5(\mathrm{n}=$ 5) d after intraperitoneal injection. Food intake, body weight, bacterial translocation, serum $\alpha$-amyloid protein, and different biochemical parameters were analyzed. Oral administration of $L$. salivarius CECT5713 to mice had no adverse effects on mouse body weight or food intake. No bacteremia was shown and there was no treatment-associated bacterial translocation to the liver or spleen. Intraperitoneal administration caused a significant bacterial translocation to the liver and spleen, but not to the blood. However, this translocation was not related to illness or death at either d 2 or d 5 , although an increase in plasma serum $\alpha$-amyloid protein was observed at $\mathrm{d} 2$. These results suggest that the strain $L$. salivarius CECT5713 is nonpathogenic for mice, even in doses 10,000 times higher (expressed per kilograms of body weight) than those normally consumed by humans. Thus, this strain is likely to be safe for human consumption.
\end{abstract}

Key words: probiotic, translocation, safety, mice

\section{INTRODUCTION}

Although the use of lactic acid bacteria (LAB) in fermented food dates back many centuries (Ballongue, 1998), in the last 2 decades there has been an increasing

Received October 18, 2006.

Accepted April 10, 2007.

${ }^{1}$ Corresponding author: flara@pulevabiotech.es interest in the use of these bacteria for nutritional and even medical applications, taking advantage of their capacity to modulate intestinal microbiota. Thus, the health-promoting effects of probiotic bacteria, most of them included in the LAB group, are well documented both in animal models and in clinical trials. These include anti-infection properties (Isolauri et al., 1991), beneficial effects in intestinal inflammation (Perán et al., 2005), immunomodulatory activity (Olivares et al., 2006), and efficacy in the prevention of allergic diseases (Furrie, 2005). The health benefits described for probiotics make them good candidates for functional foods, and a high number of new bacterial strains are being identified and incorporated into food and pharmaceutical products.

In the selection of new probiotic strains, safety criteria are applied, such as a long history of use in humans and the absence of pathogenic mechanisms (Collins et al., 1998). However, some reports have identified LAB as being associated with clinical pathological conditions such as bacteremia (Bayer et al., 1978) and occasionally endocarditis and abscess (Aguirre and Collins, 1993), although these studies are rare and it is unlikely that LAB were the causative agent in these cases (Gasser, 1994). These reports have resulted in concern about the safety of these probiotic bacteria, particularly those strains that are being introduced into the human food chain. Thus, safety assessments are recommended for probiotic strains that are aimed at being incorporated into food products (Conway, 1996).

Recently, a new potential probiotic strain has been isolated and characterized in our laboratory, Lactobacillus salivarius CECT5713. This strain has been isolated from breast milk and infant feces of a motherchild pair (Marín et al., 2006). Concerning its probiotic characteristics, L. salivarius CECT5713 has been shown to survive in gastrointestinal tract conditions, to adhere to intestinal cells, and to have antimicrobial activity (Marín et al., 2006). Because its probiotic potential suggests that this strain could be of interest for human consumption, we decided to perform an oral safety assessment to preclude deleterious effects. With this aim, mice were administered doses 500 to 10,000 
times higher (per kilogram of BW) than those normally consumed by humans, and oral toxicity, biochemical and clinical parameters, and bacterial translocation were analyzed. To preclude toxicity even in the case of potential translocation, a group of mice were injected intraperitoneally with the bacteria and the harmful effects of the translocation of bacteria to different tissues were evaluated.

\section{MATERIALS AND METHODS}

\section{Animals}

Fifty male Balb/C mice, aged 6 to $8 \mathrm{wk}$, bred at the Universidad de Granada facilities (Granada, Spain) were housed in stainless-steel cages with a 12-h light/ dark cycle ( 0800 to $2000 \mathrm{~h}$ ) in a controlled atmosphere (temperature $22 \pm 2^{\circ} \mathrm{C}$, humidity $55 \pm 2 \%$ ). The animals were fed a purified diet ad libitum (Harlan, Barcelona, Spain) and had free access to water during the experimental protocol. The protocol was carried out according to the guidelines of the Helsinki declaration and was approved by the Ethics Committee on Animal Experiments of the Universidad de Granada.

\section{Experimental Design}

After $7 \mathrm{~d}$ of acclimation, mice were randomly assigned into 1 of 5 experimental groups ( $\mathrm{n}=10$ per group) as follows: 3 groups were orally administered with either $5 \times 10^{8}, 2 \times 10^{9}$, or $10^{10} \mathrm{cfu} /$ mouse per d dissolved in skim milk for $28 \mathrm{~d}$ ( $0.1 \mathrm{~mL} /$ mouse per d). One additional group received the vehicle alone and was used as a control. Intragastric feeding was performed by means of a polyvinyl chloride tube feeding needle purchased from Vygon (Ecoue, France). The last group received intraperitoneal administration of a single dose of $5 \times$ $10^{8} \mathrm{cfu} /$ mouse dissolved in saline solution $(0.1 \mathrm{~mL} /$ mouse) and animals were killed at d $2(\mathrm{n}=5)$ and $\mathrm{d} 5$ $(\mathrm{n}=5)$ after intraperitoneal injection. Throughout the experiment, the activity, behavior, and general health of the animals were observed daily. Body weight and food intake were recorded once a week. Mice were killed by intraperitoneal administration of sodium pentothal (50 mg/kg), and blood was collected by cardiac puncture in EDTA-containing tubes in sterile conditions. The liver and spleen were removed in sterile conditions and weighed. The thymus, kidney, and heart were also removed from the intraperitoneally injected mice and weighed.

\section{Bacterial Translocation}

Bacterial translocation was analyzed in the blood, liver, and spleen. A 50- $\mu \mathrm{L}$ quantity of blood was cul- tured in de Man, Rogosa, Sharpe (MRS) agar medium and brain heart infusion (BHI) agar and incubated at $37^{\circ} \mathrm{C}$ for $48 \mathrm{~h}$ anaerobically for MRS and aerobically for BHI. Tissue samples were homogenized in buffered peptone water $(1 \mathrm{~g} / \mathrm{mL})$ and $100 \mu \mathrm{L}$ of the resulting homogenates were cultured in MRS and BHI agar as previously mentioned. After $48 \mathrm{~h}$ of incubation, colonyforming units were counted and the results were expressed as incidence of translocation (number of mice in which colony-forming units were detected/total number of mice). Positive growth on agar plates was defined by the presence of any microorganism (even a single colony).

\section{Identification of Bacteria by PCR}

For detection of $L$. salivarius CECT5713, PCR was performed directly from MRS agar colonies using the following specific primers: 5'-GAT CGC TAT TTT TTT ATT AGG TAT C- $3^{\prime}$ and 5'-TGG CTA ACT TGT TTT TTT ACT TC-3'.

\section{Serum $\alpha$-Amyloid Protein}

With the aim of analyzing plasma markers of sepsis in mice injected intraperitoneally with the bacteria, plasma serum $\alpha$-amyloid (SAA) concentration was measured with an ELISA kit (Biosource, Camarillo, CA). A $100-\mu \mathrm{L}$ quantity of plasma or standard was added to each well of a microtiter plate previously coated with a monoclonal antibody specific for SAA. Immediately, $50 \mu \mathrm{L}$ of a peroxidase-conjugated antimouse SAA was also added to each well. After $1 \mathrm{~h}$ of incubation at $37^{\circ} \mathrm{C}$, $100 \mu \mathrm{L}$ of tetramethylbenzidine was added to wells and the reaction was stopped by addition of $100 \mu \mathrm{L}$ of $\mathrm{H}_{2} \mathrm{SO}_{4}$ $(2 M)$. Finally, optical density was measured at $450 \mathrm{~nm}$ using a microplate spectrophotometer (Bio-Rad Laboratories, Hercules, CA).

\section{Total Liver Glutathione Concentration}

A 100-mg quantity of liver from each mouse was homogenized in a 7.5\% TCA solution by means of an UltraTurrax homogenizer (Heidolph, Barcelona, Spain) and homogenates were centrifuged at 3,000 $\times g$ for $10 \mathrm{~min}$ at $4^{\circ} \mathrm{C}$. Total glutathione (GSH) concentration was measured in the supernatants using a colorimetric commercial kit (OxisResearch, Portland, OR). Briefly, 40 $\mu \mathrm{L}$ of the homogenates or the standards was added to each well of a microtiter plate, together with $40 \mu \mathrm{L}$ of a reducing agent [tris(2-carboxyethyl)phosphine in $\mathrm{HCl}$, $40 \mu \mathrm{L}$ of a chromogen (1-methyl-3-chloro-7trifluoromethylquinolinium methylsulfate in $\mathrm{HCl}$ ), and $40 \mu \mathrm{L}$ of color developer $(\mathrm{NaOH})$. After $30 \mathrm{~min}$ of incuba- 
Table 1. Body and tissue weights of mice treated orally with different doses of Lactobacillus salivarius CECT5713 for $28 \mathrm{~d}^{1}$

\begin{tabular}{|c|c|c|c|c|}
\hline \multirow[b]{2}{*}{ Item } & \multicolumn{4}{|c|}{ Dose } \\
\hline & Control & $\begin{array}{c}5 \times 10^{8} \\
\text { cfu/mouse } \\
\text { per d }\end{array}$ & $\begin{array}{c}2 \times 10^{9} \\
\text { cfu/mouse } \\
\text { per d }\end{array}$ & $\begin{array}{c}10^{10} \\
\text { cfu/mouse } \\
\text { per d }\end{array}$ \\
\hline Initial weight, $\mathrm{g}$ & $18.30 \pm 0.93$ & $18.50 \pm 0.65$ & $18.37 \pm 0.73$ & $18.36 \pm 0.67$ \\
\hline Final weight, $\mathrm{g}$ & $20.32 \pm 1.41$ & $20.46 \pm 1.10$ & $20.41 \pm 1.10$ & $20.24 \pm 1.24$ \\
\hline Weight increase, \% & $11.05 \pm 1.32$ & $10.58 \pm 2.53$ & $11.12 \pm 2.10$ & $10.23 \pm 1.67$ \\
\hline Food intake, g/mouse per $\mathrm{d}$ & $2.93 \pm 0.35$ & $2.85 \pm 0.40$ & $2.73 \pm 0.38$ & $2.93 \pm 0.43$ \\
\hline Liver weight, mg & $1,041 \pm 33$ & $1,053 \pm 110$ & $1,029 \pm 115$ & $1,009 \pm 96$ \\
\hline Spleen weight, mg & $94.7 \pm 11.6$ & $96.6 \pm 13$ & $95.9 \pm 23$ & $89.9 \pm 17$ \\
\hline
\end{tabular}

${ }^{1}$ Data are means $(n=10) \pm$ SD.

tion at room temperature and in the dark, optical density was measured at $415 \mathrm{~nm}$ using a microplate spectrophotometer (Bio-Rad Laboratories).

\section{Malondialdehyde Plasma Concentration}

Malondialdehyde (MDA) plasma concentration was measured by separation with HPLC, by using a previously described method based on thiobarbituric acid reaction and reverse-phase separation with fluorescence detection (Fukunaga et al., 1998).

\section{Evaluation of the General Health Status of Mice}

To evaluate possible changes in physiological functions, because of the oral treatment with bacteria, glucose concentration and glutamic-oxalacetic transaminase (GOT) activity were measured in plasma samples by means of a commercial kit (Stangest Biomedical IND, Tarragona, Spain).

Blood cell counts (white and red cells) were also analyzed with an automatic hematology counter (Minos, ABX, Montpellier, France) on fresh blood, to evaluate possible modifications due to infection caused by oral administration of the bacteria.

\section{Statistical Analysis}

All results are expressed as the mean \pm standard deviation. Differences between means were tested for statistical significance using one-way ANOVA and post hoc least significance tests. Differences between proportions (bacterial translocation incidence) were analyzed with the chi-squared test. All statistical analyses were carried out with the Statgraphics 5.0 software package (STSC Inc., Rockville, MD), with statistical significance set at $P<0.05$.

\section{RESULTS}

\section{Oral Administration of Different Doses of $L$. salivarius CECT5713}

During the experimental protocol, no noticeable activity or behavioral changes were observed in the mice and no illness or death occurred. There was no difference in aspect between animals in the treatment and control groups.

Oral administration of $L$. salivarius CECT5713 had no adverse effects on mouse food intake; there was no difference in food intake between the control and treatment groups throughout the experiment (Table 1). As shown in Table 1, no significant difference was observed in BW gain between the control group and the groups treated orally.

Concerning tissue weights, there were no significant differences in liver and spleen weights between control mice and those receiving oral administration of $L$. salivarius CECT5713 (Table 1). Previous studies in our laboratory showed that the higher dose of the potential probiotic $\left(10^{10} \mathrm{cfu} / \mathrm{d}\right)$ did not cause changes $(P>0.1)$ in the weight of other tissues, such as the thymus, kidney, heart, or colon weight/length ratio in control mice compared with treated mice $\left(10^{10} \mathrm{cfu} / \mathrm{d}\right)$. In agreement with the absence of clinical symptoms in mice, plasma GOT activity and glucose concentration did not change, even in the group receiving the highest dose of $L$. salivarius CECT5713 (10 ${ }^{10}$ cfu/mouse per d; Table 2).

The incidence of translocation of bacteria from the gut to different tissues is shown in Table 3. No bacteremia was observed in any of the experimental groups. There was also no statistically significant difference in the incidence of translocation to the liver or spleen between the control and treated groups at any of the tested doses. In addition, colonies found on agar plates were checked by conventional PCR using specific primers, and none of the colonies corresponded to the admin- 
Table 2. Biochemical and hematological data in control and Lactobacillus salivarius CECT5713-treated mice $\left(10^{10} \mathrm{cfu} / \text { mouse per } \mathrm{d}\right)^{1}$

\begin{tabular}{lcc}
\hline Item & Control & $\begin{array}{c}\text { Dose, } 10^{10} \\
\text { cfu/mouse per d }\end{array}$ \\
\hline Leukocytes, cells/mL & $3,987 \pm 1,663$ & $3,987 \pm 1,664$ \\
Red blood cells, cells/mL & $6.4 \times 10^{6} \pm 3.1 \times 10^{5}$ & $7.4 \times 10^{6} \pm 1.2 \times 10^{6}$ \\
Glutamic-oxalacetic transaminase, IU/L & $184.3 \pm 80.6$ & $199.8 \pm 118.0$ \\
Glucose, g/L & $125.0 \pm 14.3$ & $136.4 \pm 11.0$ \\
\hline
\end{tabular}

${ }^{1}$ Data are means $(\mathrm{n}=10) \pm \mathrm{SD}$.

istered strain L. salivarius CECT5713 (data not shown).

To detect signs of infection due to treatment, the oxidative status of mice was analyzed. With this aim, liver GSH concentration and plasma MDA concentration were determined. As shown in Table 4, oral administration of $L$. salivarius CECT5713 caused a decrease $(P<0.05)$ in the liver content of GSH. This decrease was not dose dependent, because there was no difference between the groups receiving different doses of the potential probiotic. In contrast, plasma concentration of MDA did not show changes, either between the control and treatment groups or between the groups receiving different doses of the potential probiotic.

\section{Intraperitoneal Administration of L. salivarius CECT5713}

As shown in Table 5, intraperitoneal administration caused a significant translocation of $L$. salivarius CECT5713 to the liver and spleen. Although the presence of bacteria in the liver was similar 2 and $5 \mathrm{~d}$ after intraperitoneal injection, in the spleen the incidence of bacterial translocation was lower at $d 5$, even though the difference was statistically significant only for bacteria grown in MRS. In contrast, no bacteremia was shown in any of the mice injected intraperitoneally with L. salivarius CECT5713. The presence of bacteria in the liver and spleen was accompanied by a significant increase in liver weight at $\mathrm{d} 2$ and in spleen weight at d 2 and 5 (Table 6), whereas the weight of the other analyzed tissues (thymus, heart, and kidney) did not change (data not shown).

In spite of bacterial translocation to the liver and spleen and the increase in these tissue weights, no noticeable behavioral changes were observed and there was no illness or death related to $L$. salivarius CECT5713 administration. In addition, there were no significant changes in mouse BW throughout the $5 \mathrm{~d}$ after intraperitoneal injection (Table 6).

Intraperitoneal injection of L. salivarius CECT5713 did not statistically modify the plasma concentration of MDA, a marker of oxidative stress, because the plasma MDA concentration was similar to that of the control mice. In contrast, a decrease in the hepatic GSH content was observed at $\mathrm{d} 2$ after injection, although at $\mathrm{d} 5$ the hepatic content of GSH was similar to that of the control mice (Table 6). Plasma concentration of SAA, an acutephase protein reported to be increased in sepsis (Dofferhoff et al., 1992), was significantly increased in mice $2 \mathrm{~d}$ after injection, but it returned to basal values at $\mathrm{d}$ 5 (Table 6). Concerning the hematology results, intra-

Table 3. Incidence of bacterial translocation to the blood, liver, and spleen in mice treated with different doses of Lactobacillus salivarius CECT5713 ${ }^{1}$

\begin{tabular}{|c|c|c|c|c|}
\hline \multirow[b]{2}{*}{ Item $^{2}$} & \multicolumn{4}{|c|}{ Dose } \\
\hline & Control & $\begin{array}{c}5 \times 10^{8} \\
\text { cfu/mouse } \\
\text { per d }\end{array}$ & $\begin{array}{c}2 \times 10^{9} \\
\text { cfu/mouse } \\
\text { per d }\end{array}$ & $\begin{array}{c}10^{10} \\
\text { cfu/mouse } \\
\text { per d }\end{array}$ \\
\hline \multicolumn{5}{|l|}{ Blood } \\
\hline MRS & $0 / 10$ & $0 / 10$ & $0 / 10$ & $0 / 10$ \\
\hline BHI & $0 / 10$ & $0 / 10$ & $0 / 10$ & $0 / 10$ \\
\hline \multicolumn{5}{|l|}{ Liver } \\
\hline MRS & $3 / 10(32-234)$ & $2 / 10(6-60)$ & $2 / 10(49-345)$ & $0 / 10$ \\
\hline BHI & $5 / 10(50-800)$ & $5 / 10(60-900)$ & $3 / 10(20-265)$ & $2 / 10(35-190)$ \\
\hline \multicolumn{5}{|l|}{ Spleen } \\
\hline MRS & 1/10 (32) & $0 / 10$ & $1 / 10(43)$ & $2 / 10(25-85)$ \\
\hline BHI & $1 / 10(130)$ & $0 / 10$ & $1 / 10$ (105) & $0 / 10$ \\
\hline
\end{tabular}

${ }^{1}$ Numbers in parentheses represent the range of bacteria expressed as colony-forming units per organ.

${ }^{2} \mathrm{MRS}=$ de Man, Rogosa, Sharpe agar medium; BHI = brain heart infusion agar. 
Table 4. Liver glutathione (GSH) content and plasma concentration of malondialdehyde (MDA) in mice treated with different doses (cfu/mouse per d) of Lactobacillus salivarius CECT5713 ${ }^{1}$

\begin{tabular}{lcccc}
\hline & \multicolumn{4}{c}{ Dose } \\
\cline { 2 - 5 } & Control & $\begin{array}{c}5 \times 10^{8} \\
\text { cfu/mouse } \\
\text { per d }\end{array}$ & $\begin{array}{c}2 \times 10^{9} \\
\text { cfu/mouse } \\
\text { per d }\end{array}$ & $\begin{array}{c}10^{10} \\
\text { cfu/mouse } \\
\text { per d }\end{array}$ \\
\hline Liver GSH, $\mu \mathrm{mol} / \mathrm{g}$ & $9.11 \pm 1.38$ & $7.41 \pm 1.01^{*}$ & $7.72 \pm 0.95^{*}$ & $7.71 \pm 0.73^{*}$ \\
Plasma MDA, $\mu M$ & $4.57 \pm 1.20$ & $4.89 \pm 1.03$ & $4.18 \pm 1.03$ & $3.99 \pm 0.40$ \\
\hline
\end{tabular}

${ }^{1}$ Data are means $(\mathrm{n}=10) \pm \mathrm{SD}$.

$* P<0.05$ vs. the control.

peritoneal injection did not significantly modify the number of red blood cells and leukocytes.

\section{DISCUSSION}

During the last several years, there has been increasing interest in the manipulation of intestinal microbiota with probiotics, which has resulted in the isolation of new LAB strains to be included in food and pharmaceutical products. For this reason, the safety of these probiotics has been the subject of active discussion. Although there have been no general guidelines on this issue until now, acute oral toxicity has been proposed as a fundamental test for the assessment of probiotic safety (Stine and Brown, 1996) and has been applied previously in safety assessment studies (Donohue et al., 1993; Zhou et al., 2000).

Oral toxicity assessment showed that mice treated orally with huge doses of the potential probiotic strain L. salivarius CECT5713 were healthy and survived daily administration after $28 \mathrm{~d}$. No adverse effects were observed on BW and food intake, indicating that the potential probiotic does not exhibit gross oral toxicity, and no deleterious effects were shown on the health status, growth, or development of the animals. In addi-

Table 5. Incidence of translocation in mice injected intraperitoneally with $5 \times 10^{8} \mathrm{cfu} /$ mouse of Lactobacillus salivarius CECT5713 at d 2 and 5 after injection ${ }^{1}$

\begin{tabular}{clll}
\hline Item $^{2}$ & \multicolumn{1}{c}{ Control } & \multicolumn{1}{c}{ Day 2} & \multicolumn{1}{c}{ Day 5} \\
\hline Blood & & & \\
MRS & $0 / 10$ & $0 / 5$ & $0 / 10$ \\
BHI & $0 / 10$ & $0 / 5$ & $0 / 10$ \\
Liver & & & \\
MRS & $3 / 10(50-230)$ & $5 / 5^{*}(90-1,800)$ & $4 / 5^{*}(98-1,116)$ \\
BHI & $5 / 10(90-900)$ & $5 / 5^{*}(312-1,025)$ & $4 / 5^{*}(50-1,130)$ \\
Spleen & & & \\
MRS & $1 / 10(55)$ & $5 / 5^{*}(185-1,024)$ & $1 / 4 \dagger(24)$ \\
BHI & $1 / 10(98)$ & $5 / 5^{*}(193-880)$ & $2 / 5^{* \dagger}(25-45)$ \\
\hline
\end{tabular}

\footnotetext{
${ }^{1}$ Numbers in parentheses represent colony-forming units per organ.

${ }^{2} \mathrm{MRS}=$ de Man, Rogosa, Sharpe agar medium; BHI = brain heart infusion agar.

$* P<0.05$ vs. control; $\dagger P<0.05$ vs. $\mathrm{d} 2$.
}

tion, no dose-dependent effect was observed in any of the parameters measured, thus suggesting the absence of a treatment-related deleterious effect.

Bacterial translocation is a recommended indicator of probiotic toxicity, because it is the first step in the pathogenesis process for many opportunistic strains indigenous to the lumen (Steffen and Berg, 1983). In spite of the high doses of bacteria administered to mice, there was no bacteremia in any of the treated groups. We obtained bacterial cells from the liver and spleen (see Table 3), but in no case was $L$. salivarius CECT5713 found, and the incidence was similar in mice receiving the potential probiotic compared with control mice, thus suggesting that translocation was not associated with treatment. These data suggest that high doses of the test potential probiotic administered orally to mice do not cause bacterial translocation to the blood, spleen, or liver. The presence of some bacteria in the liver and spleen was previously described in healthy mice (Ma et al., 1990). According to our results, there were no signals of sepsis in mice because the plasma concentration of MDA, an oxidative stress marker (Gil et al., 2006), was similar in the control and treatment groups. Regarding the hepatic content of GSH, an increase in this parameter has been reported to be related to the acute phase of sepsis (Malmezat et al., 1998), but to our knowledge a decrease has not been reported to be clinically significant in sepsis. Although the decrease observed in the hepatic content of GSH in our experimental model was not related to any symptoms of infection, further investigation is needed to elucidate the biological relevance of this decrease.

In agreement with the absence of any symptoms of infection in mice treated orally with the bacteria, the blood markers of physiological functions (GOT and glucose), as well as the red blood cell and leukocyte counts, did not show any statistically significant difference compared with those of the control mice.

Although the data pointed to the fact that $L$. salivarius CECT5713 was not able to translocate from the gut to other tissues, we decided to induce this translocation by intraperitoneal administration of $L$. salivarius 
Table 6. Different clinical and biochemical data at $\mathrm{d} 2$ and 5 after intraperitoneal injection $\left(10^{8} \mathrm{cfu} / \mathrm{mouse}\right)$ of Lactobacillus salivarius CECT5713 ${ }^{1}$

\begin{tabular}{lccc}
\hline Item & Control & Day 2 & Day 5 \\
\hline Initial BW, g & $18.69 \pm 0.91$ & $19.19 \pm 1.27$ & $18.94 \pm 1.75$ \\
Final BW, g & $19.01 \pm 0.85$ & $19.63 \pm 1.45$ & $19.82 \pm 1.46$ \\
Liver weight, mg & $1,041 \pm 33$ & $1,116 \pm 70^{*}$ & $1,086 \pm 13^{*}$ \\
Spleen weight, mg & $94.7 \pm 11.6$ & $120.1 \pm 14.6^{*}$ & $158.6 \pm 16.4^{*}$ \\
Plasma malondialdehyde, mM & $4.57 \pm 1.20$ & $3.63 \pm 0.32$ & $5.68 \pm 2.50$ \\
Liver glutathione, $\mu$ mol/g of tissue & $9.11 \pm 1.38$ & $7.09 \pm 0.64^{*}$ & $8.54 \pm 0.46$ \\
Plasma serum $\alpha$-amyloid, pg/mL & $31.7 \pm 17.1$ & $388.8 \pm 83.9^{*}$ & $49.23 \pm 82.7$ \\
Red blood cells, cells/mL & $6.2 \times 10^{6} \pm 3.0 \times 10^{5}$ & $5.8 \times 10^{6} \pm 2.5 \times 10^{5}$ & $6.5 \times 10^{6} \pm 2.8 \times 10^{5}$ \\
Leukocytes, cells/mL & $3,987 \pm 1,664$ & $4,152 \pm 1,782$ & $3,853 \pm 1,663$ \\
\hline
\end{tabular}

${ }^{1}$ Values are mean $(n=10$ for control; $n=5$ for $d 2$ and 5$) \pm$ SD.

$* P<0.05$ vs. control.

CECT5713 with the aim of precluding adverse effects even in this case. The injection of $L$. salivarius CECT5713 caused a significant initial translocation of the bacteria to the liver and spleen, which produced a significant increase in liver and spleen weights. This increase was probably caused by a transient inflammatory process that could be maintained over time, even in the absence of bacteria. This could explain why the spleen weights did not return to normal values at $d 5$ in spite of the fact that translocation of the bacteria decreased. In contrast, bacterial translocation did not induce behavioral changes, and there was no illness or death in the injected mice. Intraperitoneal administration of the same dose of other pathogenic microorganisms, such as different strains of Escherichia coli, has been reported to be lethal for mice at d 2 after inoculation (Gras et al., 2006). In the case of $L$. salivarius CECT5713 administration, an immediate response was observed at $d 2$, mainly shown by the increase in the acute-phase protein SAA, but at d 5 this protein returned to basal values, thus suggesting a transitory and slight inflammatory response. Although more studies will be needed to elucidate the significance of the decrease in hepatic GSH content, our results did not show any signs of illness related to this decrease.

These results, suggesting the safety of $L$. salivarius CECT5713 in the case of translocation, are in agreement with previously published results. Perán et al. (2005) evaluated the effect of $L$. salivarius CECT5713 in a rat model of intestinal inflammation, a pathology related to increased intestinal permeability. Even in these intestinal conditions, oral treatment with L. salivarius CECT5713, far from being deleterious, showed a beneficial effect, improving clinical manifestation of the inflammation.

In summary, feeding mice with the new LAB strain L. salivarius CECT5713 at high doses for $28 \mathrm{~d}$ had no deleterious effects on mice. Even in the case of translocation, toxicity of the bacteria seemed to be negligible. These data, together with other important safety prop- erties of L. salivarius CECT5713, such as its human milk origin and the absence of D-lactic acid production (Marín et al., 2006), a critical parameter for its use in infant nutrition, allow us to conclude that this strain is likely to be safe for human consumption.

\section{ACKNOWLEDGMENTS}

The authors are grateful to Alberto Zafra from the Analytical Department of Puleva Biotech S.A. for his help in the measurement of plasma MDA concentration. We would also like to thank Manuel Carlos Olivares for assistance in the measurement of biochemical and hematological parameters and Julio Boza for his help in the interpretation and discussion of results.

\section{REFERENCES}

Aguirre, M., and M. D. Collins. 1993. Lactic acid bacteria and human clinical infection. J. Appl. Bacteriol. 75:95-107.

Ballongue, J. 1998. Bifidobacteria and probiotic action. Page 519 in Lactic Acid Bacteria-Microbiology and Functional Aspects. 2nd ed. S. Salminen and A. Von Wright, ed. Marcel Dekker, New York, NY.

Bayer, A. S., A. W. Chow, D. Betts, and L. B. Guze. 1978. Lactobacillemia-Report of nine cases. Important clinical and therapeutical considerations. Am. J. Med. 64:808-813.

Collins, J. K., G. Thorton, and G. O. Sullivan. 1998. Selection of probiotic strains for human applications. Int. Dairy J. 8:487-490.

Conway, P. L. 1996. Selection criteria for probiotic microorganisms. Asia Pac. J. Clin. Nutr. 5:10-14.

Dofferhoff, A. S., V. J. Bom, H. G. de Vries-Hospers, J. van Ingen, J. vd Meer, B. P. Hazenberg, P. O. Mulder, and J. Weits. 1992. Patterns of cytokines, plasma endotoxin, plasminogen activator inhibitor, and acute-phase proteins during the treatment of severe sepsis in humans. Crit. Care Med. 20:185-192.

Donohue, D. C., M. Deighton, J. T. Ahokas, and S. Salminen. 1993. Toxicity of lactic acid bacteria. Page 369 in Microbiology and Functional Aspects. 2nd ed. S. Salminen and A. Von Wright, ed. Marcel Dekker, New York, NY.

Fukunaga, K., M. Yoshida, and N. Nakazono. 1998. A simple, rapid, highly sensitive and reproducible quantification method for plasma malondialdehyde by high-performance liquid chromatography. Biomed. Chromatogr. 12:300-303.

Furrie, E. 2005. Probiotics and allergy. Proc. Nutr. Soc. 64:465-469.

Gasser, F. 1994. Safety of lactic acid bacteria and their occurrence in human clinical infections. Bull. Pasteur Inst. 92:45-67. 
Gil, L., W. Siems, B. Mazurek, J. Gross, P. Schroeder, P. Voss, and T. Grune. 2006. Age-associated analysis of oxidative stress parameters in human plasma and erythrocytes. Free Radic. Res. 40:495-505.

Gras, V., B. Bouffandeau, P. H. Montravers, and J. D. Lalau. 2006. Effect of metformin on survival rate in experimental sepsis. Diabetes Metab. 32:147-150.

Isolauri, E., M. Juntunen, T. Rautanen, P. Sillanauke, and T. Koiuva. 1991. A human Lactobacillus strain (Lactobacillus casei sp. strain GG) promotes recovery from acute diarrhea in children. Pediatrics 88:90-97.

Ma, L., E. Deitich, R. Specian, E. Steffen, and E. Berg. 1990. Translocation of Lactobacillus murinus from the gastrointestinal tract. Curr. Microbiol. 80:177-184.

Malmezat, T., D. Breuillé, C. Pouyet, P. P. Mirand, and C. Obled. 1998. Metabolism of cysteine is modified during the acute phase of sepsis in rats. J. Nutr. 128:97-105.

Marín, R., E. Jiménez, M. Olivares, M. L. Marín, L. Fernández, J. Xaus, and J. M. Rodriguez. 2006. Lactobacillus salivarius CECT5713, a potential probiotic strain isolated from infant feces and breast milk of a mother-child pair. Int. J. Food Microbiol. 112:35-43.
Olivares, M., M. P. Díaz-Ropero, N. Gómez, F. Lara-Villoslada, J. A. Maldonado, R. Martín, E. López-Huertas, J. M. Rodriguez, and J. Xaus. 2006. Oral administration of two probiotic strains, Lactobacillus coryniformis CECT5711 and Lactobacillus gasseri CECT5714, enhances the intestinal function of healthy adults. Int. J. Food Microbiol. 107:104-111.

Perán, L., D. Camuesco, M. Comalada, A. Nieto, A. Concha, M. P. Díaz-Ropero, M. Olivares, J. Xaus, A. Zarzuelo, and J. Galvez. 2005. Preventive effects of a probiotic, Lactobacillus salivarius ssp. salivarius, in the TNBS model of rat colitis. World J. Gastroenterol. 11:5185-5192.

Steffen, E. K., and R. D. Berg. 1983. Relationship between caecal population levels of indigenous bacteria and translocation to the mesenteric lymph nodes. Infect. Immun. 39:1215-1259.

Stine, K. E., and T. M. Brown. 1996. Measuring toxicity and assessing risk. Pages 1-10 in Principles of Toxicology. K. E. Stine and T. M. Brown, ed. CRC Press, Boca Raton, FL.

Zhou, J. S., Q. Shu, K. J. Rutherfurd, J. Prasad, K. P. Gopal, and H. S. Gill. 2000. Acute oral toxicity and bacterial translocation studies on potentially probiotic strains of lactic acid bacteria. Food Chem. Toxicol. 38:153-161. 